\title{
Postoperative atrial fibrillation is not an innocuous arrhythmia in patients with left ventricular assist devices
}

Cipriano Abad, MD, PhD, FEBS (Hon, Gen Surg), EBCTS, ${ }^{a}$ Stefano Urso, MD, PhD, ${ }^{a}$ and Bernardino Clavo, MD, $\mathrm{PhD}^{\mathrm{b}}$

From the ${ }^{\mathrm{a}}$ Department of Cardiovascular Surgery, Hospital Universitario de Gran Canaria Dr Negrin, Las Palmas de Gran Canaria, Spain; and ${ }^{\mathrm{b}}$ Research Unit, Hospital Universitario de Gran Canaria Dr Negrin, Las Palmas de Gran Canaria, Spain.

Disclosures: Authors have nothing to disclose with regard to commercial support.

Received for publication April 10, 2018; revisions received April 18, 2018; accepted for publication April 18, 2018; available ahead of print May 16, 2018.

Address for reprints: Cipriano Abad, MD, PhD, FEBS (Hon, Gen Surg), EBCTS, Hospital Universitario de Gran Canaria Dr Negrin, Barranco de La Ballena sn, Las Palmas de Gan Canaria 35010, Spain (E-mail: cprnabad2@ gmail.com).

J Thorac Cardiovasc Surg 2018;156:1550-1

$0022-5223 / \$ 36.00$

Copyright (c) 2018 Published by Elsevier Inc. on behalf of The American Association for Thoracic Surgery https://doi.org/10.1016/j.jtcvs.2018.04.087

In this issue of the Journal, Hawkins and coworkers ${ }^{1}$ provide an interesting and valuable retrospective study. Information was collected from a regional database (the Virginia Cardiac Services Quality Initiative) derived from 7 hospitals that perform cardiac surgery. Hawkins and coworkers ${ }^{1}$ reviewed the records of 1064 patients who had a continuous-flow left ventricular assist device (LVAD; HeartMate II, HeartMate III; St Jude Medical Inc, St Paul, Minn; or HeartWare; HeartWare International Inc, Framingham, Mass) implanted from 2009 to 2016. Among these 1064 patients, 375 (35\%) had a history of preoperative atrial fibrillation (AF). Of the 689 patients without preoperative AF, $121(17.6 \%)$ had postoperative AF (POAF) develop, and these were compared with the 568 who did not have POAF. The groups had similar cardiopulmonary bypass times, aortic crossclamp times, and hospital mortality. In univariate analysis, the POAF group had many more morbidities (higher rate of right ventricular assist device implantation, increased risk of renal failure, higher resource use, longer intensive care unit stay, and longer hospital stay). In the group with POAF, the median hospital and intensive care unit costs were significantly higher (\$30,000 USD in hospital costs and more than $\$ 4000$ USD in intensive care unit-related costs).

This article points out 3 interesting and important issues in patients with LVADs and POAF: (1) They had more postoperative complications. (2) They had a significantly increased hospital resource use. (3) Right ventricular failure was a possible contributor to the POAF.

Heart failure as emerged as a growing health problem in Western countries. As the population ages, the number of patients with cardiac failure increases. LVAD therapy represents the best alternative for many patients with advanced symptomatic heart failure that does not respond to conventional medical treatment and for those who are not candidates

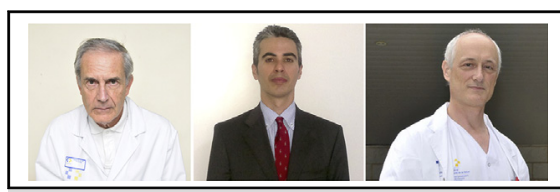

Left to right: Cipriano Abad, MD, PhD, FEBS (Hon, Gen Surg), EBCTS, Stefano Urso, MD, PhD, Bernardino Clavo, MD, PhD

Central Message

Postoperative atrial fibrillation is not a innocuous arrhythmia in patients with left ventricular assist devices.

See Article page 1543.

for percutaneous interventions, resynchronization therapy, cardiac surgery, or heart transplantation. Furthermore, the limited availability of donors has increased the number of patients who receive a durable LVAD as destination therapy. LVAD therapy represents a significant modern contribution in the treatment of patients with advanced heart failure and can be lifesaving in cases of cardiogenic shock. Mechanical support with LVAD improves not only patients' survival but also their quality of life.

$\mathrm{AF}$ is the most common supraventricular arrhythmia, and it is frequently found in patients with advanced heart failure. With the increasingly LVAD use in these patients, a greater number have preoperative $\mathrm{AF}^{2}$ and this therapy may contribute to POAF. The incidence and repercussions of AF in patients with LVADs can be significant, and strategies to diminish this arrhythmia should be undertaken.

Surgeons may wish to consider concomitant interventions with LVAD insertion to reduce the risk of POAF, including repair of tricuspid valve regurgitation, implantation of right ventricular assist devices in patients with right ventricular dysfunction, surgical exclusion of the left atrial appendage, or use of catheter or surgical ablation techniques. In addition, aggressive pharmacologic or electric cardioversion for POAF may reduce its complications.

Today, cardiac surgeons should also be involved in the financial implications and costs of their procedures. According to Kilic and coworkers, ${ }^{3}$ postoperative complications are the primary drivers of cost variations. The costs of LVAD therapy might be reduced by decreasing postoperative morbidity and readmissions. ${ }^{4}$ Prevention of postoperative complications is an important target for the heart team. 
Hawkins and colleagues ${ }^{1}$ are to be congratulated for their contribution to our understanding of the potential causes of LVAD complications. Further research is required to determine the most effective methods to predict and treat POAF after LVAD implantation.

\section{References}

1. Hawkins RB, Mehaffi JH, Guo A, Charles EJ, Speir AM, Rich JB, et al. Postoperative atrial fibrillation is associated with increased morbidity and resource utilization after left ventricular assist device placement. J Thorac Cardiovasc Surg. 2018;156:1543-9.

2. Xia Y, Stern D, Friedmann P, Golstein D. Preoperative atrial fibrillation may no increase thromboembolic events in left ventricular assist device recipients on midterm follow-up. J Heart Lung Transplant. 2016;35:906-12.

3. Kilic A, Sha AS, Conte JV, Mandak K, Baumgartner W, Cameron DE, et al. Un derstanding variability in hospital-specific costs of coronary artery bypass grafting represents an opportunity for standardizing care and improving resource use. $J$ Thorac Cardiovasc Surg. 2014;147:109-15.

4. Shih T, Dimick JB. Reducing the cost of left ventricular assist devices: why it mat ters and can it be done? J Thorac Cardiovasc Surg. 2018;155:2466-8. 